\title{
Encaminhamento de crianças para atendimento psicológico e diagnóstico psiquiátrico dos pais
}

\section{Children's referral to psychological service and parents' psychiatric diagnosis}

\author{
Carla Renata Lacerda* \\ Universidade Presbiteriana Mackenzie, São Paulo, São Paulo, Brasil
}

\author{
Geraldo Antônio Fiamenghi J únior** \\ Universidade Presbiteriana Mackenzie, São Paulo, São Paulo, Brasil
}

\begin{abstract}
RESUMO
Objetivou-se, nesta pesquisa, analisar a relação entre o encaminhamento da criança, para atendimento psicológico, e a presença de transtorno psiquiátrico em um dos pais. Realizou-se um levantamento nos prontuários das crianças encaminhadas para o serviço de psicologia de um ambulatório público de Saúde Mental, em uma cidade do interior do Estado de São Paulo. Surgiram quatro categorias de análise: presença de transtorno mental num dos pais, diagnosticado com a CID; presença de transtorno mental em algum familiar, o qual reside com a criança; referência de transtorno mental num dos pais, sem diagnóstico clínico; adversidades no ambiente familiar. Parece haver uma relação significativa entre sintomas apresentados pelas crianças e ambiente familiar, envolvendo transtorno mental dos pais, além do risco para a ocorrência de abuso. Afirma-se a necessidade de uma abordagem de atendimento familiar, incluindo ações preventivas em saúde e educação.
\end{abstract}

Palavras-chave: Família, Pais, Criança, Transtornos psiquiátricos, Prontuários.

\begin{abstract}
This research aimed to analyze the relationship between the referral of children to psychological service and the presence of psychiatric disabilities in parents. A search was conducted in records of children referred to the Psychological Service in a Mental Health public service in São Paulo State. Four categories appeared: presence of mental illness in one of the parents diagnosed with CID; presence of mental illness in any family member living with the child; reference to mental illness in one of the parents, without clinical diagnosis; problems in family environment. There seems to be a significant relation between symptoms presented by children and family environment, involving mental illness, as well as the risk for abuse. The need for a family intervention approach is stated, including preventive actions in health and education.
\end{abstract}

Keywords: Family, Parents, Child, Psychiatric disabilities, Records. 


\section{I ntrodução}

A literatura psicanalítica, desde as primeiras publicações de Freud, despertou-nos para a importância que as experiências infantis possuem no desenvolvimento psíquico da criança, além de sustentar a estrita necessidade da família enquanto suporte e núcleo organizador para o desenvolvimento emocional dos filhos.

Teóricos da psicanálise, de um modo geral, atentos às transformações em torno do grupo familiar, ao estudarem o desenvolvimento infantil, destacaram a importância de se examinar a complexidade das relações que se estabelecem na esfera familiar. Ackerman (1982) afirma que a família é essencial para o desenvolvimento pessoal e para a adaptação à vida, devendo ser entendida como uma unidade social e emocional, com o propósito de regulação ou direção social. Desta forma, as experiências de vida familiar deixam uma profunda e duradoura impressão em todos nós. Isto acontece tendo em vista que, internamente, a esfera familiar é composta por uma rede dinâmica e interativa de relacionamentos entre os pais, entre pais e filhos e finalmente entre os filhos. Em se tratando de uma unidade familiar, autores como Berenstein (1976) e Carter e McGoldrick (1995) nos lembram que, tanto a criança quanto a família, ao longo da vida, defrontam-se com os chamados períodos críticos. Situações vividas no ambiente familiar como o divórcio, recasamento e doença crônica são fatores de transição de um estágio para outro no processo de vida familiar e nestes momentos de mudanças, o estresse familiar manifesta-se e intensifica-se podendo constituir fatores de desintegração familiar (CARTER, MCGOLDRICK, 1995). Segundo Berenstein (1976), a família enquanto sistema possui um conjunto de relações recíprocas às quais o comportamento do indivíduo está vinculado: o seu comportamento é determinado e determinante. A família do doente mental possui uma organização cindida: uma das partes é formada pelo doente e a outra pelos sadios, trata-se de uma formação duradoura que se cristaliza por anos e busca no contexto social o marco para legitimar esta organização.

Ao avaliar o papel do ambiente familiar nos distúrbios psicológicos da criança, Ackerman (1982), considera que o surgimento do distúrbio psicológico na criança, em geral, é precedido pelo conflito familiar; a psicopatologia é uma resposta não somente às características individuais dos pais, mas também às distorções apresentadas do que é ser um casal conjugal e parental; se a criança é tratada e a desordem familiar ignorada, a criança novamente adoece; se a criança melhora, outros membros da família podem adquirir alguma melhora ou piora; os conflitos e ansiedade num membro da família dificultam a terapia da criança e, se a família é tratada assim como a 
criança, é possível conciliar os objetivos da terapia com aqueles de prevenção de transtorno mental.

Vitolo et al. (2005) sugerem que determinadas práticas educativas podem predizer o comportamento da criança, isto é, práticas caracterizadas por atenção, interesse positivo e comportamento moral são variáveis preditoras de comportamentos pró-sociais e práticas negativas como negligência, descaso, falta de atenção e omissão são preditoras de distúrbio de comportamento.

Ao investigar a prevalência e os fatores de risco para saúde mental em escolares e sua possível relação com as crenças e atitudes educativas dos pais, Salvo e colaboradores (2005) mostraram que a presença dos casos clínicos limítrofes para saúde mental foi de $35,2 \%$, tendo como sintomas mais frequentes ansiedade/depressão, seguido dos problemas de conduta, hiperatividade/déficit de atenção e problemas de relacionamento com colegas, sendo a maioria do sexo masculino. Pais que acreditavam na punição física como método educativo agrediam os filhos com maior frequência e as crianças punidas com cinto apresentavam maior taxa de hiperatividade e problemas de conduta quando comparadas àquelas não punidas nestes moldes. As crianças, cujos pais tinham problema de transtorno mental, demonstraram mais problemas de conduta, dificuldades emocionais e de relacionamento.

No trabalho de Ferreira e Marturano (2002), ficou demonstrado que o ambiente familiar das crianças com problema de comportamento externalizante apresenta menos recursos e maior adversidade, como problemas nas relações interpessoais, falhas parentais quanto à supervisão, indícios de menor investimento dos pais no desenvolvimento da criança, práticas punitivas e modelos adultos agressivos. Os pesquisadores salientam que nesta população existe elevado risco para distúrbio psicossocial na adolescência e, desta forma, as intervenções não devem se restringir às questões escolares, mas abranger o sistema familiar de forma preventiva. Martins et al. (2004) buscaram identificar os fatores de risco associados à qualidade do ambiente doméstico e as características de crianças expostas e constataram que $15,40 \%$ viviam em ambiente negativo; dentre os fatores de risco levantados encontram-se baixa renda familiar, baixa escolaridade materna, casa com numerosos residentes, número de filhos igual ou superior a quatro, uso de tabaco na gestação, crianças compartilhando a cama com os pais e mães com transtornos psiquiátricos. Este último fator é destacado pelos pesquisadores como tendo significativa relação com a qualidade do ambiente familiar, visto que as mães cujos indicadores de suspeita de transtorno mental foram menores apresentaram ambientes positivos.

Outro aspecto estudado por Winnicott (1965/2005) refere-se, mais precisamente, aos efeitos dos transtornos psicológicos presentes nos 
pais sobre o ambiente familiar, observando que "o distúrbio psiconeurótico do pai ou da mãe acarreta certas complicações para a criança; a psicose de um dos pais, porém suscita perigos mais sutis para o desenvolvimento sadio" (p.74).

Em um estudo descritivo, Noroño et al. (2002) concluíram que nas famílias cuja presença de alcoolismo, manifestações de agressividade, transtornos mentais entre outros predominaram, o comportamento agressivo na criança foi prevalente. Furtado, Laucht e Schmidt (2006) concluíram que crianças de pais alcoolistas apresentam alto risco para psicopatologia; além disso, tanto filhos quanto filhas possuem elevado risco para desenvolvimento de comportamento agressivo e delinquente. Enquanto na infância precoce, os meninos e as meninas de pai alcoolista apresentaram padrões parecidos de comportamento exteriorizado, na fase pré-pubere as meninas apresentaram uma significativa tendência a apresentar comportamentos internalizados como queixas somáticas, fobias, ansiedade generalizada e depressão quando comparadas ao grupo controle, cujos pais não tinham diagnóstico de alcoolismo. No estudo de Souza et al. (2005) ficou demonstrado também que filhas de alcoolistas apresentam mais problemas emocionais e comportamentais que filhas de não alcoolistas. E ainda Figlie et al. (2004) mostraram que na maioria das famílias em que o pai é o dependente químico de álcool, nas crianças observou-se timidez, sentimento de inferioridade, depressão, conflito familiar, carência afetiva.

Quando se considera a violência intrafamiliar, Scodelário (2002) identifica aspectos disfuncionais, como uma comunicação deficiente, onde as ações fortes e violentas substituem os meios verbais para se expressar o que sente; um complô do silêncio que favorece a continuidade dos abusos e sua reprodução dentro do mesmo grupo familiar; a utilização intensa de mecanismos psicológicos de defesa, sobretudo, a negação da violência sofrida e rebaixamento da autoestima da vítima. A família abusiva possui sérias dificuldades em reconhecer, aceitar e respeitar os limites, onde o abuso do poder é exercido de forma arbitrária com excesso de transgressão e ausência de interdição imposta pela cultura. Assis (2002) e Minayo (2006) apontam que além dos agravos orgânicos como lesões físicas, traumatismos, hematomas, queimaduras, fraturas em decorrência dos abusos sofridos, as crianças apresentam sintomas psicológicos associados, como sentimentos de raiva, de medo do agressor, dificuldade de aprendizagem, desconfiança, distúrbios de comportamento (dispersão, fobias, agressividade, passividade, isolamento social), atitudes erotizadas precoces, dificuldade de socialização.

Em situações de abuso sexual intrafamiliar, Habgzang et al. (2005) encontraram significativa presença de pais agressivos, com problemas de álcool e outras drogas e transtornos mentais; também 
estiveram presentes na dinâmica familiar, outros tipos de abuso como violência física ou psicológica e negligência. Estudos que investigaram crianças hospitalizadas por lesões físicas, como traumatismos (COLLI et al, 1997), queimaduras (Camargo et al, 2002), acidentes (HARADA et al, 2000; SALCEDO, CARVALHO, 2005), a partir de uma análise cuidadosa de seus prontuários, demonstram um predomínio do sexo masculino; em geral, as agressões quando presentes possuem uma alta subnotificação como agente externo e são camufladas entre os chamados eventos de intenção indeterminada ou pseudoacidentes praticados por familiares ou conhecidos.

Dois estudos, também baseados na análise de registros em prontuários de Conselhos Tutelares, os quais analisaram, especificamente, a atuação deste órgão frente aos casos de violência contra a criança (SANTOS, 2002; MARTINS, ANDRADE, 2005) constataram: uma alta subnotificação tanto da vítima quanto do agente agressor nestes casos de violência intrafamiliar, o domicílio da criança como sendo o local privilegiado para tais ocorrências, a falta de uma intervenção sistemática e criteriosa do Conselho e o fator resultante mais grave deste quadro discutido por Santos (2002) refere-se a revitimização da criança, por parte daqueles a quem supostamente coube oferecer proteção e um trabalho efetivo, quando da falência dos recursos de suas respectivas famílias.

Assim, o objetivo deste trabalho foi analisar as relações entre o encaminhamento da criança para atendimento psicológico e a presença de transtorno psiquiátrico em um dos pais, presentes nos prontuários de um ambulatório de saúde pública.

\section{Método}

\subsection{Local e Coleta dos Dados}

A pesquisa foi realizada no Ambulatório de Saúde Mental do SUS (Sistema Único de Saúde) de uma cidade do interior de São Paulo.

Foi realizado um levantamento nos prontuários das crianças encaminhadas para o serviço de psicologia com os seguintes critérios de inclusão ou categorias previamente definidas:

1. I dade das crianças compreendida entre 5 e 14 anos completos;

2. Não ter concluído o atendimento psicológico, abandonando-o;

3. Presença de transtorno mental num dos pais.

O segundo critério de inclusão justifica-se porque o abandono do atendimento implicava finalização dos prontuários, permitindo o acesso dos pesquisadores, além de ser um aspecto recorrente observado pela equipe técnica do Ambulatório. 
Após a aprovação da pesquisa pelo Comitê de Ética em Pesquisa da Universidade (CEP/UPM no 1034/03/2008 e CAAE o 0011.0.272.00008), foi assinado o Termo de Consentimento Livre e Esclarecido pela Secretaria Municipal de Saúde do município e a consulta aos prontuários foi realizada.

\subsection{Tratamento e análise dos dados coletados}

A partir do critério de inclusão previamente estabelecido foi analisado o motivo do encaminhamento de cada criança, sua idade à época do atendimento e a CID (Classificação Internacional das Doenças) que constava no prontuário de um dos pais aberto no serviço de Saúde Mental, CAPS (Centro de Atenção Psicossocial) ou Ambulatório para tratamento. Estas informações constam na folha de Triagem de Saúde Mental, que é realizada com todos os casos encaminhados para serviço de Saúde Mental, tanto CAPS, quanto ambulatório. Isto possibilitou a identificação de transtorno mental num dos pais devidamente diagnosticada com sua respectiva CID-10, além de se observar situações pertinentes a esta pesquisa que, do nosso ponto de vista não podiam ser desprezadas, pois se referiam a mais de um caso e nos remetiam a uma análise mais abrangente do ambiente familiar da criança. Tais informações possibilitaram a construção das seguintes categorias de análise:

1. Presença de diagnóstico psiquiátrico com a respectiva CID-10 num dos pais ou ambos da criança encaminhada;

2. Presença de diagnóstico psiquiátrico com a respectiva CID-10 em algum integrante da família mais extensa da criança encaminhada; aqui se incluiu avô e avó, tios maternos e paternos, que em geral residiam no mesmo ambiente doméstico da criança ou a criança encontrava-se sob os cuidados da referida pessoa;

3. Ausência de diagnóstico psiquiátrico sem $\mathrm{CID}$, porém referência a transtorno mental no pai ou na mãe da criança encaminhada, ou seja, o serviço de Saúde Mental não foi procurado, pois não constava abertura de prontuário;

4. Ausência de diagnóstico psiquiátrico sem $\mathrm{CID}$, porém o contexto familiar da criança encaminhada enfrenta modificações, adversidades e conflitos familiares, como adoção, morte de um dos pais, separação dos pais, nascimento de irmão, disputa judicial, abuso físico e abuso sexual;

Em cada categoria, foi indicado o tipo de abuso identificado na análise de acordo com as modalidades propostas por Minayo (2006).

\section{Resultados e discussão}


Para melhor visualizar os casos apresentados, estes foram divididos em 4 tabelas que permitiram expor as principais relações observadas nos prontuários tanto das crianças quanto dos pais/responsáveis.

A Tabela 1 permite correlacionar os motivos de encaminhamento das crianças com o diagnóstico psiquiátrico dos pais, além do tipo de abuso sofrido. Nela constatamos o transtorno mental diagnosticado em maior número de mães das crianças do que em pais; os diagnósticos são bem variados estando relacionados aos seguintes tipos de transtornos: neuróticos (F40; F41; F41.2), afetivos (F31;F32;F34) psicóticos $(F 20 ; F 25)$ e por substâncias psicoativas (F10;F13). Embora haja diversificação quanto aos motivos dos encaminhamentos realizados, houve maior queixa quanto à ansiedade e agressividade nas crianças encaminhadas, sendo que os tipos de abuso mais frequentes foram negligência, abuso psicológico e físico, predominando crianças com idade entre 5 e 11 anos. Um dado que chama à atenção é a criança cujo pai faz uso de substância psicoativa (álcool), a mãe possui um quadro de psiconeurose e a avó é dependente de substância sedativa.

\section{TABELA 1}

Diagnóstico psiquiátrico com a respectiva CID num dos pais ou ambos da criança encaminhada e ocorrência de abuso.

\begin{tabular}{|c|c|c|}
\hline $\begin{array}{l}\text { MOTIVO DO ENCAMINHAMENTO/IDADE DA } \\
\text { CRIANÇA }\end{array}$ & $\begin{array}{l}\text { PAIS/DIAGNÓSTICO } \\
\text { PSIQUIÁTRICO }\end{array}$ & $\begin{array}{l}\text { TIPO DE ABUSO } \\
\text { IDENTIFICADO }\end{array}$ \\
\hline $\begin{array}{l}\text { 1. CAPS encaminha filha de paciente internada. } / 14 \\
\text { anos }\end{array}$ & Mãe / F 20 & Negligência dos Pais \\
\hline $\begin{array}{l}\text { 2. Enurese, gagueira, agitado, dificuldade de } \\
\text { relacionamento interpessoal e dificuldade de } \\
\text { aprendizagem./ } 11 \text { anos }\end{array}$ & Pai / F 20 & Abuso Psicológico \\
\hline $\begin{array}{l}\text { 3. Sente-se sozinha, ansiedade, auto-agressão, } \\
\text { alucinação auditiva./ } 14 \text { anos }\end{array}$ & Mãe / F 41.2 & \\
\hline $\begin{array}{l}\text { 4. Ansiedade, chorosa, encaminhamento médico./ } \\
9 \text { anos }\end{array}$ & Mãe / F 32 & \\
\hline $\begin{array}{l}\text { 5. Ansiedade, agressiva, bate nos colegas./ } 5 \\
\text { anos }\end{array}$ & Mãe F 40 & $\begin{array}{l}\text { Abuso Físico e } \\
\text { Psicológico }\end{array}$ \\
\hline $\begin{array}{l}\text { 6. Depressão encaminhada pelo neurologista./ } 10 \\
\text { anos }\end{array}$ & Mãe / F 40 & $\begin{array}{l}\text { Suspeita de Abuso } \\
\text { Sexual }\end{array}$ \\
\hline $\begin{array}{l}\text { 7. Hiperatividade, encam inhado pelo clínico. / } 6 \\
\text { anos }\end{array}$ & Mãe / F41 & $\begin{array}{l}\text { Abuso Físico e } \\
\text { Psicológico }\end{array}$ \\
\hline $\begin{array}{l}\text { 8. Tiques constantes, ansiedade, irritabilidade./ } 8 \\
\text { anos }\end{array}$ & Mãe / F 60 & Abuso Psicológico \\
\hline $\begin{array}{l}\text { 9. Agitado, furto, encaminhado pelo Conselho } \\
\text { Tutelar. } 9 \text { anos }\end{array}$ & $\begin{array}{l}\text { Mãe / F 41.2; } \\
\text { Pai / F 10; } \\
\text { Avó m aterna / F13 }\end{array}$ & Negligência dos Pais \\
\hline 10. Agressividade, ansiedade./ 9 anos & Pai /F34 & \\
\hline $\begin{array}{l}\text { 11. Indisciplina, agressividade, problemas na } \\
\text { escola./ } 11 \text { anos }\end{array}$ & Mãe F25 & Negligência Paterna \\
\hline 12. Irritação, agressividade./ 3 anos & Mãe / F31 & Negligência \\
\hline
\end{tabular}


Já a tabela 2 apresenta o segundo tipo de informação obtida, relacionando os motivos de encaminhamento da criança com algum membro da família extensa da criança responsável por ela, além de identificar o tipo de abuso sofrido.

\section{TABELA 2}

Diagnóstico psiquiátrico com a respectiva $\mathrm{CID}$ em algum integrante da família mais extensa da criança encaminhada

\begin{tabular}{|l|l|l|}
\hline \multicolumn{1}{|c|}{$\begin{array}{c}\text { MOTIVO DO ENCAMINHAMENTO/IDADE } \\
\text { DA CRIANÇA }\end{array}$} & $\begin{array}{c}\text { FAMILIAR/ } \\
\text { DIAGNÓSTICO } \\
\text { PSIQUIÁTRICO }\end{array}$ & $\begin{array}{l}\text { TIPO DE ABUSO } \\
\text { IDENTIFICADO }\end{array}$ \\
\hline 1. Encoprese, medo, sono agitado./ 6 anos & $\begin{array}{l}\text { Tio materno / F20.5 } \\
\text { Tio paterno / F10 }\end{array}$ & $\begin{array}{l}\text { Abuso Físico e } \\
\text { Psicológico }\end{array}$ \\
\hline 2. Agressividade./ 11 anos & Avó materna / F32 & \\
\hline 3. Abuso sexual, ansiedade./ 12 anos & Avó materna / F41.2 & Abuso Sexual \\
\hline $\begin{array}{l}\text { 4. Agressividade, comportamento auto- } \\
\text { agressivo./ 8 anos }\end{array}$ & Avó materna / F33 & \\
\hline $\begin{array}{l}\text { 5. Ansiedade, fuga domiciliar e escolar./ 11 } \\
\text { anos }\end{array}$ & Tia materna / F20 & Abuso Físico \\
\hline $\begin{array}{l}\text { 6. Ansiedade, irritabilidade./ 11 anos } \\
\text { 7. Agressividade, ansiedade, alucinações } \\
\text { visuais./ 7 anos }\end{array}$ & Avô paterno / F33.3 & Negligência \\
\hline $\begin{array}{l}\text { 8. Tia busca o serviço, agitado, } \\
\text { confabulação./ 9 anos }\end{array}$ & $\begin{array}{l}\text { Tia materna / F 29 } \\
\text { Avó materna / F13 } \\
\text { Tios maternos / F20; } \\
\text { F20 }\end{array}$ & $\begin{array}{l}\text { Abuso Físico e } \\
\text { Psicológico }\end{array}$ \\
\hline 9. Hiperatividade, agressividade./ 5 anos & Avó materna / F41.2 & \\
\hline
\end{tabular}

Na tabela acima observa-se um aspecto interessante, indicando que a presença de doença mental num familiar que convive e é responsável pela criança foi mais evidente na figura da avó materna, seguido dos tios maternos. Os transtornos aqui diagnosticados foram os psicóticos (F20, F20.5, F29), de humor (F32,F33,F33.3), neuróticos (F41.2) e por substâncias psicoativas (F10,F13) sendo que os transtornos de humor aqui identificados estão relacionados a quadros depressivos. Nas crianças, predominam as queixas de agressividade e ansiedade tendo o abuso físico e o psicológico como os tipos mais recorrentes.

\section{TABELA 3}


Ausência de diagnóstico psiquiátrico sem CID, com presença de transtorno mental no pai ou na mãe da criança encaminhada

\begin{tabular}{|c|c|c|}
\hline MOTIVO DO ENCAMINHAMENTO/IDADE & $\begin{array}{l}\text { REFERÊNCIA DE } \\
\text { DOENÇA MENTAL }\end{array}$ & $\begin{array}{l}\text { TIPO DE ABUSO } \\
\text { IDENTIFICADO }\end{array}$ \\
\hline $\begin{array}{l}\text { 1. Irritabilidade, dor de barriga, impulsivo, } \\
\text { furto, agitado./ } 10 \text { anos }\end{array}$ & Mãe: Depressão & $\begin{array}{l}\text { Abuso Físico e } \\
\text { Psicológico }\end{array}$ \\
\hline 2. Humor oscilante, crise de nervoso./ 11 anos & Mãe: Depressão & $\begin{array}{l}\text { Abuso Físico e } \\
\text { Psicológico }\end{array}$ \\
\hline 3. Irritabilidade./ 10 anos & Pai : Alcoolismo & \\
\hline 4. Encoprese, enurese, ansioso./ 7 anos & Pai : Ansiedade & Negligência \\
\hline $\begin{array}{l}\text { 5. Irritado, nervoso, auto-agressão, verbaliza } \\
\text { que quer morrer./ } 6 \text { anos }\end{array}$ & $\begin{array}{l}\text { Mãe: Depressão } \\
\text { Pai: Tentativa de } \\
\text { suicidio }\end{array}$ & $\begin{array}{l}\text { Abuso Físico e } \\
\text { Psicológico }\end{array}$ \\
\hline 6. Transtorno comportamental./ 11 anos & $\begin{array}{l}\text { Pai: Alcoolismo } \\
\text { Avô paterno: } \\
\text { Alcoolismo }\end{array}$ & Negligência \\
\hline 7. Agressividade, sintomas somáticos./ 5 anos & $\begin{array}{l}\text { Pai : Alcoolismo e } \\
\text { Drogadição }\end{array}$ & $\begin{array}{l}\text { Abuso Físico e } \\
\text { Psicológico }\end{array}$ \\
\hline $\begin{array}{l}\text { 8. Disritmia, agressividade, irritabilidade./ } \\
8 \text { anos }\end{array}$ & $\begin{array}{l}\text { Mãe: Drogadição } \\
\text { Pai (falecido): } \\
\text { Drogadiç̧ão } \\
\text { Avós maternos: } \\
\text { Alcoolismo }\end{array}$ & $\begin{array}{l}\text { Abuso Físico e } \\
\text { Psicológico. Suspeita } \\
\text { de Abuso Sexual }\end{array}$ \\
\hline $\begin{array}{l}\text { 9. Desobediente, desmotivada, irritabilidade, } \\
\text { ansiedade./ } 8 \text { anos. }\end{array}$ & $\begin{array}{l}\text { Mãe: Psicose, } \\
\text { internação }\end{array}$ & \\
\hline
\end{tabular}

O terceiro tipo de dados obtidos diz respeito a uma ausência de diagnóstico psiquiátrico dos pais, mas com referência de transtorno mental neles, havendo a priori, uma equivalência tanto no pai quanto na mãe e os quadros psiquiátricos registrados dizem respeito à dependência química de álcool ou drogas e depressão. Algumas informações complementares ajudam a reforçar tais referências; no caso 1 há histórico de depressão recorrente nesta mãe em diversos momentos de sua vida: em sua adolescência ao descobrir que era filha adotiva, quando teve seu primeiro filho que é a criança encaminhada em questão e novamente quando este ingressou na escola; no caso 8 em que existe suspeita de abuso sexual, isto recai sobre o avô da criança que referem ser alcoolista e a própria mãe fora abusada por ele na infância, o que reforça tais suspeitas. De uma maneira geral, os tipos de abusos mais frequentes foram o abuso físico e o psicológico.

Quando juntamos os dados referentes às Tabelas 1 e 3 , isto é, a presença de transtornos psiquiátricos nos pais e o encaminhamento das crianças, vamos encontrar uma alta correlação entre o desequilíbrio parental e as situações de negligência e/ou maus tratos para com as crianças $\left(X^{2} 0,0011\right)$. Na maioria das vezes, a criança 
que vive com a mãe com transtornos psiquiátricos tem mais possibilidade de sofrer negligência ou abuso do que aquelas cujo pai tem transtornos psiquiátricos. A figura 1 mostra a relação entre mães e pais com transtornos psiquiátricos e a frequência de abusos/maus tratos sofridos pelas crianças.

\section{FI GURA 1}

Comparação entre Mãe e Pai com Transtornos Psiquiátricos e Negligência/Abuso em Crianças

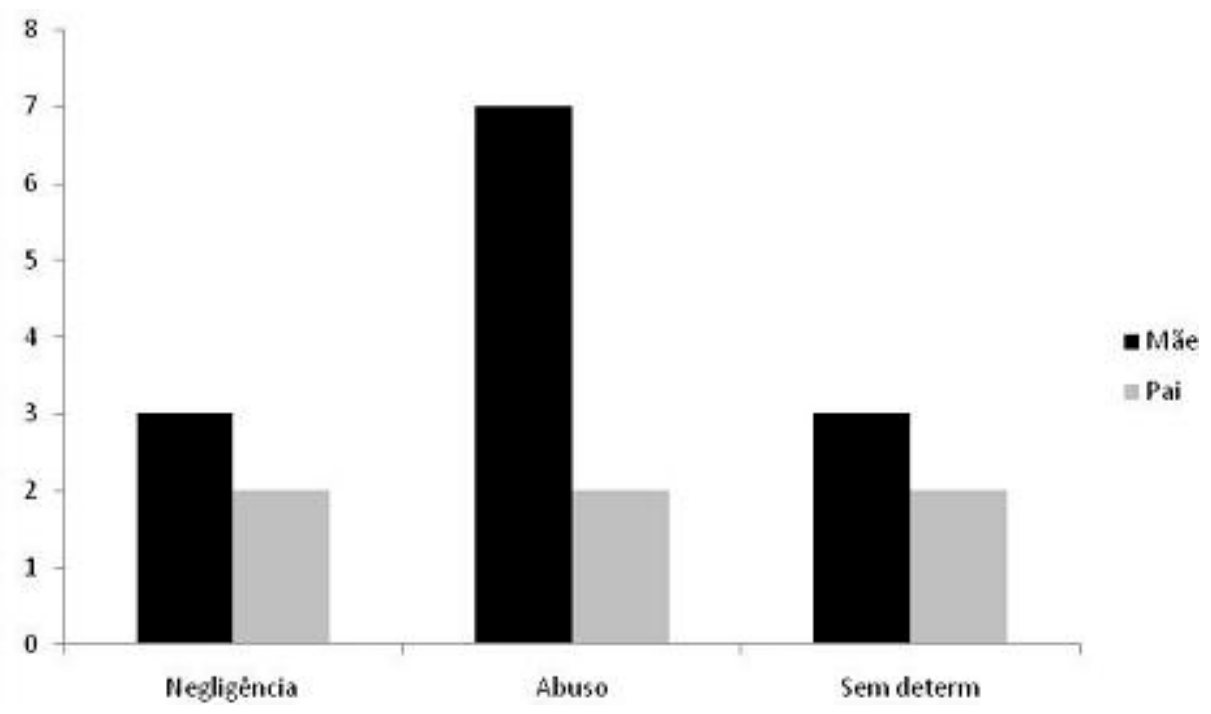

Finalmente, no quarto tipo de dados, aparecem dificuldades na família, que levaram a transtornos emocionais nas crianças. Os dados aqui descritos permitem observar que o encaminhamento da criança é concomitante a algum tipo de situação familiar adversa, com a presença de conflitos e crises dos mais variados tipos, que de alguma forma relacionam-se com ele. O motivo do encaminhamento mostrase bastante variado, porém a queixa mais referida foi angústia. Quanto à ocorrência de abuso, os tipos mais explícitos aqui são o abuso psicológico e o abuso físico, que estão associados em muitos casos. É importante salientar que em dois casos a constatação de abuso psicológico e de abuso físico foi trazida como queixa pelo encaminhamento. $\mathrm{O}$ abuso psicológico refere-se ao caso 2 , pois se trata da disputa judicial pela guarda da criança entre a mãe e avó materna, sendo que esta última faz ameaças e chantagens verbais à criança de que caso ela fique com a mãe a avó irá suicidar-se.

\section{TABELA 4}


Ausência de diagnóstico psiquiátrico sem CID - contexto familiar da criança encaminhada enfrenta modificações, adversidades e conflitos familiares

\begin{tabular}{|c|c|c|}
\hline $\begin{array}{l}\text { MOTIVO DO ENCAMINHAMENTO/IDADE } \\
\text { DA CRIANÇA }\end{array}$ & $\begin{array}{l}\text { STTUAÇÃO } \\
\text { FAMILIAR }\end{array}$ & $\begin{array}{l}\text { TIPO DE ABUSO } \\
\text { IDENTIFIC ADO }\end{array}$ \\
\hline $\begin{array}{l}\text { 1. Taquicardia, ir ritabilidade, encoprese/ } 12 \\
\text { anos }\end{array}$ & Questão religiosa & Abuso Físico \\
\hline 2. Ir ritabilidade, angústia// 9 anos & $\begin{array}{l}\text { Disputa judicial pela } \\
\text { guarda da criança }\end{array}$ & Abuso Psicológico \\
\hline $\begin{array}{l}\text { 3. Encaminhada pelo Conselho Tutelar; } \\
\text { recusa ir à escola } \sqrt{ } 8 \text { anos }\end{array}$ & $\begin{array}{l}\text { Criança reside com } \\
\text { avós e não com os } \\
\text { pais }\end{array}$ & Negligência dos Pais \\
\hline 4. Irritailidade auto-agressão./ 8 anos & $\begin{array}{l}\text { Não é filho biológico } \\
\text { do pai }\end{array}$ & Abuso Psicológico \\
\hline 5. Angústia, irritabilidade./ 9 anos & $\begin{array}{l}\text { Separação dos pais; } \\
\text { falecimento da mãe }\end{array}$ & \\
\hline 6. Agitada, ir ritada./ 9 anos & $\begin{array}{l}2^{\circ} \text { casamento do pai; } \\
\text { abuso físico }\end{array}$ & $\begin{array}{l}\text { Abuso Físico e } \\
\text { Psicológico }\end{array}$ \\
\hline 7. Agressivo, abuso sexual / 8 anos & Pais separados & Abuso Sexual \\
\hline $\begin{array}{l}\text { 8. Hiperatividade, enca minhado pelo } \\
\text { neur ologista } \sqrt{ } 6 \text { anos }\end{array}$ & Questão religiosa & Negligência dos Pais \\
\hline 9. Enurese, bruxismo, irritabilidade / 7 anos & Adoção & Abandono \\
\hline 10. Confabulação, furto./ 9 anos & $\begin{array}{l}\text { Divergência e } \\
\text { inadequação parental }\end{array}$ & Negligência dos Pais \\
\hline 11. Ansiedade./ 9 anos & Falecimento do pai & \\
\hline 12. Irritado, fala que quer morrer./ 8 anos & $\begin{array}{l}\text { Divergência e } \\
\text { inadequação parental }\end{array}$ & Abuso Psicológico \\
\hline $\begin{array}{l}\text { 13. Irritabilidade, preocupação, medo, } \\
\text { ameça matar-se// } 11 \text { anos }\end{array}$ & Separação dos pais & \\
\hline 14. Irritabilidade, medo, timidez./ 5 anos & $\begin{array}{l}\text { Separação dos pais; } \\
\text { criança mora com avó }\end{array}$ & $\begin{array}{l}\text { Suspeita de Abuso } \\
\text { Físico }\end{array}$ \\
\hline $\begin{array}{l}\text { 15. Episódios de auto-agressão, angústia, } \\
\text { irritabilidade// } 13 \text { anos }\end{array}$ & & \\
\hline $\begin{array}{l}\text { 16.Irritabilidade, mágoa dos pais e da } \\
\text { madrasta./ } 13 \text { anos }\end{array}$ & $\begin{array}{l}\text { Abuso físico e } \\
\text { psic ológico de sua } \\
\text { madrasta }\end{array}$ & $\begin{array}{l}\text { Abuso Físico e } \\
\text { Psicológico }\end{array}$ \\
\hline $\begin{array}{l}\text { 17. Perda de inter esse, desmotivada, perda } \\
\text { de apetite./ } 11 \text { anos }\end{array}$ & $\begin{array}{l}\text { Pais separados; } \\
\text { reside com mãe e } \\
\text { padrasto }\end{array}$ & \\
\hline
\end{tabular}

Em termos gerais a análise realizada nos prontuários também permitiu verificar que a participação paterna nas diversas etapas do atendimento foi nitidamente reduzida, com exceção de dois casos. $\mathrm{Na}$ ausência da mãe, quem acompanhava a criança para o atendimento era a avó materna ou tia materna. Quanto à interrupção do atendimento, este se deu em diversos momentos do processo de atendimento. Em alguns casos, geralmente a mãe discordava do encaminhamento, mas deixava claro que vinha por insistência da escola, do médico, ou para não sofrer represálias do Conselho Tutelar.

Chama-nos, inicialmente, a atenção o número de prontuários encontrados, levando-se em conta de que se trata de crianças encaminhadas para o atendimento e não tiveram o seu tratamento concluído. Outro aspecto a ser analisado nestes casos é que eles representam famílias que possuem um ou mais membros com 
transtornos mentais graves, convivendo com a criança. Ao agrupar o sintoma da criança inserida no grupo familiar que possui alguém com transtorno mental e analisá-lo, podemos estabelecer uma relação, não do ponto de vista de causa e efeito, mas como elementos ativos num sistema de relações interligadas que the conferem sentido e significado (ACKERMAN, 1982; BERENSTEIN, 1976; WINNICOTT, 1965/2005). Com isto entende-se que a vida afetiva da família é mobilizada através das correntes de sentimento que transitam entre os diversos membros da família (Ackerman, 1982) e podem sob circunstâncias alteradas, provocar uma corrente antagônica. Quanto aos tipos de transtornos mais frequentes nos pais tivemos os quadros de psicose em geral, os transtornos de humor e os transtornos causados pelo uso de álcool e drogas. Isto não significa que os transtornos isoladamente irão determinar um distúrbio ou sintoma específico na criança, mas afetarão o seu desenvolvimento (WINNICOTT, 1965/2005), dependendo da característica e padrão de sua reação (ACKERMAN, 1982), que determinarão a psicopatologia instalada, mesmo porque os sintomas apresentados como queixa se mostraram bastante variados, com nítido destaque para a agressividade, irritabilidade e ansiedade. A depressão, mais evidente nas tabelas 2 e 3, relacionada, respectivamente, à avó materna e à mãe, apresenta uma correlação significativa com os sintomas da criança, independente se a pessoa em questão é pai, mãe, tio, avó (WINNICOTT, 1965/2005).

Em relação aos quadros de dependência química de avós e pais da criança, apesar da literatura consultada não tratar especificamente dos transtornos psiquiátricos devido ao uso de álcool e drogas, existem pesquisas realizadas com filhos e filhas de alcoolistas(NOROÑO et al, 2002; FIGLIE et al, 2004; SOUZA et al, 2005; FURTADO, LAUCHT, SCHMIDT, 2006). Tais pesquisas demonstram que há um elevado risco para o desenvolvimento de comportamento agressivo e delinquente. Além disso, as filhas de alcoolistas têm mais problemas emocionais. Observamos, no nosso estudo, que estas crianças estão propensas à agressividade, à irritabilidade e à queixas somáticas.

Quanto ao abuso contra a criança, pode-se levantar a hipótese de que os casos aqui examinados estão sujeitos a este tipo de ocorrência. Teóricos do meio científico nacional (ASSIS, 2002; SALOMON, 2002; GUERRA, 2005; MINAYO, 2006;) tendem a evitar uma associação entre abuso contra a criança e transtorno mental, mas as pesquisas consultadas (CECCONELLO, DE ANTONI, KOLLER, 2003; HABIGZANG, KOLLER, AZEVEDO, 2005; MALDONADO, WILLIAMS, 2005; SALCEDO, CARVALHO, 2005) demonstraram que as crianças vitimizadas eram provenientes de ambientes familiares nos quais, dentre outros fatores de risco para a situação de abuso, havia a presença de transtornos psiquiátricos. Diante dos resultados aqui 
apresentados parece que o ambiente familiar que enfrenta adversidades, como as assinaladas, está suscetível à ocorrência de abuso. Mediante tais constatações, é muito provável, do nosso ponto de vista, que este possa ser um dos fatores que influenciaram a interrupção do tratamento pela família, uma vez que o profissional, identificando estas ocorrências, apresentaria notificação ao Conselho Tutelar. Outro aspecto que também favoreceu esta postura da família refere-se aos moldes de atendimento que, no momento, são oferecidos: a abordagem individualizada de psicoterapia para a criança o que, como Berenstein (1976) argumenta, parece reforçar a organização cindida da família, elegendo-se a criança como o seu membro doente. Não se tratando a família, como Ackerman (1982) sustenta, a desordem familiar é ignorada e a criança não se desvincula deste mecanismo patológico que se estabelece entre ela e os pais e destes entre si.

\section{Considerações finais}

Em primeiro lugar, cabe afirmar que não se trata de culpar ou penalizar a família pelas dificuldades enfrentadas. Quando se lida com pessoas que sofrem transtornos psiquiátricos, não se pode compreender que desejam propositadamente causar danos aos filhos. Esta pesquisa pretendeu mostrar que, as crianças cujos pais ou cuidadores sofrem com transtornos psiquiátricos constituem-se na parte vulnerável na estrutura familiar, o que não é percebido pelos órgãos responsáveis, especialmente o Conselho Tutelar.

Quanto aos riscos para esta população, podemos considerar que as crianças ao enfrentar adversidades em seu ambiente familiar como transtorno mental, rupturas e crises constituem um grupo de alto risco para o surgimento de distúrbios psicológicos em seu desenvolvimento, contribuindo para a formação de futuras psicopatologias e ocorrência de abuso.

O método utilizado nesta pesquisa foi efetivo, na medida em que permitiu agrupar dados e informações e correlacioná-los em relação ao grupo familiar, o que auxiliará numa futura proposta de atendimento tanto de caráter preventivo, como interventivo.

Contudo, uma importante questão presente nos prontuários foi a interrupção do tratamento das crianças, por motivos variados expostos pelos familiares, ou sem qualquer justificativa. Assim, estudos futuros poderiam comparar aqueles tratamentos concluídos satisfatoriamente, com os interrompidos, para tentar estabelecer se o sofrimento de crianças pode ser, ao menos, diminuído, a partir do trabalho psicológico e se intervenções familiares seriam um caminho para a redução das dificuldades familiares encontradas. 


\section{Referências}

ACKERMAN, N. W. The strength of family therapy. New York: Ackerman Institute for Family Therapy, 1982.

ASSIS, S. G. Crescendo em meio à violência. In: WESTPHAL, M. F. (Org.). Violência e criança. São Paulo: Editora da Universidade de São Paulo, 2002, p. 115-123.

BERENSTEIN, I. Familia y enfermedad mental. Buenos Aires: Editorial Paidós, 1976.

CAMARGO, C. L.; SAMPAIO, A. L.; XAVIER, E. A. Lesões por queimaduras: o reflexo da violência em crianças e adolescentes. Revista Brasileira de Crescimento e Desenvolvimento Humano, São Paulo, v. 12, n. 2, p. 52-58, 2002.

CARTER, B.; MCGOLDRICK, M. As mudanças no ciclo de vida familiar: uma estrutura para a terapia familiar. Porto Alegre: Artes Médicas, 1995.

CECCONELlO, A. M.; DE ANTONI, C.; KOLLER, S. H. Práticas educativas, estilos parentais e abuso físico no contexto familiar. Psicologia em Estudo, Maringá, v. 8 (número especial), p. 45-54, 2003.

COLLI, B. O.; SATO, T.; OLIVEIRA, R. S. Características dos pacientes com traumatismo craniencefálico atendidos no Hospital das Clínicas da Faculdade de Medicina de Ribeirão Preto. Arquivos de NeuroPsiquiatria, São Paulo, v. 55, n. 1, p. 91-100, 1997.

FERREIRA, M. C. T.; MARTURANO, E. M. Ambiente familiar e os problemas do comportamento apresentados por crianças com baixo nível escolar. Psicologia: Reflexão e Crítica, Porto Alegre, v. 15, n. 1, p. 35-44, 2002.

FIGLIE, N.; FONTES, A.; MORAES, E.; PAYA, R. Filhos de dependentes químicos com fatores de risco bio-psicossociais: necessitam de um olhar especial? Revista de Psiquiatria Clínica, São Paulo, v. 31, n. 2, p. 53-62, 2004.

FURTADO, E. F.; LAUCHT, M.; SCHMIDT, M. H. Gender-related pathways for behavior problems in the offspring of alcoholic fathers. Brazilian Journal of Medical and Biological Research, Ribeirão Preto, v. 39, n. 5, p. 659-669, 2006.

HABIGZANG, L. F.; KOLLER, S. H.; AZEVEDO, G. A. Abuso sexual infantil e dinâmica familiar: aspectos observados em processos jurídicos. Psicologia: Teoria e Pesquisa, Brasília, v. 21, n. 3, p. 341-348, 2005.

HARADA, M. J. C. S.; BOTTA, M. L. G; KOBATA, C. M.; SZAUTER, I. H.; DUTRA, G.; DIAS, E. C. Epidemiologia de crianças hospitalizadas por acidentes. Folha Médica, Rio de Janeiro, v. 119, n. 4, p. 43-47, 2000. 
MALDONADO, D. P. A.; WILLIAMS, L. C. A. O comportamento agressivo de crianças do sexo masculino na escola e sua relação com a violência doméstica. Psicologia em Estudo, Maringá, v. 10, n. 3, p. 353-362, 2005.

MARTINS, C. B. G.; ANDRADE, S. M. Epidemiologia dos acidentes e violências entre menores de 15 anos em município da região sul do Brasil. Revista Latino-Americana de Enfermagem, Ribeirão Preto, v. 13, n.4, p. 530-537, 2005.

MARTINS, M. F. D.; COSTA, J. S. D.; SAFORCADA, E. T.; CUNHA, M. D. C. Qualidade do ambiente e fatores associados: um estudo em crianças de Pelotas, Rio Grande do Sul, Brasil. Cadernos de Saúde Pública, Rio de Janeiro, v. 20, n. 3, p. 710-718, 2004.

MINAYO, M. C. S. Violência e saúde. Rio de Janeiro: Editora Fiocruz, 2006.

NOROÑO, N. V. M.; CRUZ, R. C.; ROSARIO CADALSO, R. S.; FERNÁNDEZ, O. B. Influencia del medio familiar em niños con conductas agresivas. Revista Cubana de Pediatria, Santiago (Cuba), v. 74, n.2, p. 138-144, 2002.

ORGANIZAÇÃO MUNDIAL DA SAÚDE - OMS. CI D 10 - Classificação de Transtornos Mentais e de Comportamento da CID-10: Descrições clínicas e diretrizes diagnósticas. Disponível em: <http://www.psicosite.com.br/cla/c_neu_som.htm>. Acesso em: 08 jun. 2010.

SALOMON, Z. Ciclos de violência. In: WESTPHAL, M. F. (Org.). Violência e criança. São Paulo: Editora da Universidade de São Paulo. 2002, p. 73-99.

SALCEDO, L. J. A.; CARVALHO, A. M. P. Maltrato infantil por agresores bajo efecto del alcohol. Revista Latino-Americana de Enfermagem, Ribeirão Preto, v. 13 (número especial), p. 827-835, 2005.

SALVO, C. G.; SILVARES, E. F. M.; TONI, P. M. Práticas educativas como forma de predição de problemas de comportamento e competência social. Estudos de Psicologia (Campinas), Campinas, v. 22, n. 2, p. 187-195, 2005.

SANTOS, M. Escola e conselho tutelar: percepções e atuações diante do fenômeno da violência doméstica contra crianças e adolescentes. 2002. 120 p. Dissertação (Mestrado em Psicologia Escolar) - Pontifícia Universidade Católica de Campinas, Campinas, 2002.

SCODELÁRIO, A. S. A família abusiva. In: FERRARI, D. C. A.; VECINA, T. C. C. (Orgs.). O fim do silêncio na violência familiar: teoria e prática. São Paulo: Ágora, 2002.

SOUZA, J.; JERONYMO, D. V.; ZANOTI, E.; CARVALHO, A. M. P. Maturidade emocional e avaliação comportamental de crianças filhas de alcoolistas. Psicologia em Estudo, Maringá, v. 10, n. 2, p. 191199, 2005. 
VITOLO, Y. L. C.; FLEITLICH-BILYK, B.; GOODMAN, R.; BORDIN, I.A.S. Crenças e atitudes educativas dos pais e problemas de saúde mental em escolares. Revista de Saúde Pública, São Paulo, v. 39, n. 15, p. 716-724, 2005.

WINNICOTT, D.W. A família e o desenvolvimento individual. São

Paulo: Martins Fontes, 1965/2005.

\author{
Endereço para correspondência \\ Carla Renata Lacerda \\ Rua Cândido Mota, 1660 \\ Vila Rodrigues - Assis - SP - CEP: 19806-250 \\ Endereço eletrônico: carlarelacerda@gmail.com \\ Geraldo Antônio Fiamenghi Júnior \\ Endereço eletrônico: gfiamenghi@hotmail.com
}

Recebido em: 18/10/2010

Reformulado em: 18/07/2011

Aceito para publicação em: 15/08/2011

Acompanhamento do processo editorial: Eleonôra Prestrelo

\title{
Notas
}

* Mestre em Distúrbios do Desenvolvimento pela Universidade Presbiteriana Mackenzie. Possui graduação em Psicologia pela Pontifícia Universidade Católica de Campinas (1995), Aprimoramento Profissional na área de Psicologia do Desenvolvimento em Pediatria pela UNICAMP (1996) e Mestre em Distúrbios do Desenvolvimento pela Universidade Presbiteriana Mackenzie (2009). Atua em área clínica, Assis, São Paulo.

**Clínica de Psicologia, São Paulo, São Paulo, Brasil. Graduação em Psicologia pela Pontifícia Universidade Católica de Campinas (1983), mestrado em Educação pela Universidade Estadual de Campinas (1987) e doutorado em Psicologia pela University of Edinburgh (1997). Tem experiência na área de clínica, docência e pesquisa em Psicologia e Educação, com ênfase em Desenvolvimento Social e da Personalidade. Atua em Clínica Particular, Campinas, São Paulo. 